\title{
VISUALISASI ALIRAN DUA FASE SOLID-GAS DI PIPA HORISONTAL DIAMETER 15,8 MM DAN 24,5 MM PADA MESIN PNEUMATIC CONVEYING
}

\author{
Zaenal Musthofa \\ Program Studi Teknik Mesin \\ Universitas Muria Kudus \\ Email: musthofazaenal16@gmail.com \\ Akhmad Zidni Hudaya \\ Program Studi Teknik Mesin \\ Universitas Muria Kudus \\ Email: akhmad.zidni@umk.ac.id \\ Masruki Kabib \\ Program Studi Teknik Mesin \\ Universitas Muria Kudus \\ Email: masruki.kabib@umk.ac.id
}

\begin{abstract}
ABSTRAK
Visualisasi merupakan salah satu cara untuk mengetahui pola aliran dan fenomena yang terjadi pada aliran dua fase. Selanjutnya optimasi produksi dan keamanan proses pada mesin pneumatic conveying dapat ditentukan berdasarkan pola aliran yang dipilih. Tujuan dari penelitian ini adalah mengetahui pola aliran dan karakteristik aliran dua fase solid gas di dalam pipa horizontal pada pneumatic conveying.

Metode yang digunakan umtuk mengetahui karakteristik aliran solid-gas yaitu, dengan melakukan pengamatan secara visual fenomena yang terjadi pada aliran pipa sepanjang $6 \mathrm{~m}$, dengan diameter dalam pipa 25,4 mm pada aliran horisontal menggunakan kamera FUJI XA5 dengan kecepatan perekaman 30 sampai 120 fps (frame per second). Kecepatan superfisial udara $\left(\mathrm{J}_{\mathrm{G}}\right.$ ) diatur dari kecepatan $2 \mathrm{~m} / \mathrm{s}$ sampai dengan 10 $\mathrm{m} / \mathrm{s}$. Sedangkan laju aliran massa solid $\left(\dot{m}_{\mathrm{S}}\right)$ diatur dari $2,2 \mathrm{~kg} / \mathrm{menit}$ sampai dengan $11 \mathrm{~kg} / \mathrm{menit}$. Pengamatan dilakukan pada jarak pipa $4750 \mathrm{~mm}$ sampai $5250 \mathrm{~mm}$ dari pengumpan. Pola aliran dua fase solid-gas ini ditandai oleh bayangan cahaya yang terdapat dicelah-celah partikel solid.

Hasil penelitian ini menunjukkan bahwa beberapa pola aliran yang terbentuk dapat diidentifikasi dengan cara visualisasi. Pola aliran yang berhasil diamati adalah dune flow, non-uniform suspended flow, slug flow dan packed bed. Pola-pola aliran yang terbentuk selanjutnya digunakan sebagai dasar pembuatan peta pola aliran yang diusulkan.
\end{abstract}

Kata kunci: Pneumatic conveying, aliran dua fase, aliran solid-gas, visualisasi.

\section{ABSTRACT}

The Visualization is one of method to determine the flow patterns and phenomena that occur in the two-phase flow. Furthermore, the selected flow pattern can be used to optimeze the production and process safety of the pneumatic conveying. The study was aimed to determine the flow pattern and flow behavior of the solid-gas two-phase flow in a horizontal pipe on pneumatic conveying.

The flow patterns were determined by visual observation. The characteristics of solid-gas two phase flow were observed by a high speed video camera. A FUJI XA5 was used as high speed video camera with frame rate video recording $120 \mathrm{fps}$ (frames per second). A transparent acrylic pipe of $6 \mathrm{~m}$ long with internal diameter $25.4 \mathrm{~mm}$ was used in the experimental series to ensure the observation of the solid-gas phenomenon. The Observations were conducted at a pipe distance of $4750 \mathrm{~mm}$ from the feeder tee. The two-phase solid-gas flow pattern were characterized by light 
shadows in the gaps of the solid particles. The superficial air velocity $\left(J_{G}\right)$ was set from $2 \mathrm{~m} / \mathrm{s}$ to 10 $m \mathrm{~s}$. Meanwhile, the solid mass flow rate $\left(\dot{m}_{S}\right)$ was set from $2.2 \mathrm{~kg} /$ minute to $11 \mathrm{~kg} /$ minute.

As results, several flow patterns were identified by visualization method. The flow patterns are dune flow, non-uniform suspended flow, slug flow and packed bed. Based on the identified flow patterns, a new flow pattern map was proposed.

Keywords : pneumatic conveying, two phase flow, solid-gas flow, visualization.

\section{PENDAHULUAN}

Sistem pneumatic conveying adalah suatu proses dimana bahan curah dari hampir semua jenis ditransfer atau dipindahkan menggunakan aliran gas sebagai media pengangkut dari satu sumber atau lebih ke satu atau banyak lagi. Udara adalah gas yang paling umum digunakan, tetapi tidak dipilih untuk digunakan dengan bahan reaktif dan dimana ada gangguan debu [1]. Salah satu faktor penting dalam suatu perancangan mesin pneumatic conveying adalah karakteristik penurunan tekanan yang terjadi pada pipa selama bahan-bahan curah tersebut ditransportasikan.

Permasalahan unik dalam aliran dua fase solid-gas adalah penurunan tekanan dan pola aliran. Permasalahan tersebut sangat dipengaruhi oleh berbagai parameter, antara lain pengaruh diameter pipa, konfigurasi pipa yang dipakai, properti fluida gas dan bahan curah, pergerakan antara fluida gas dan bahan curah, serta laju aliran fluida gas dan bahan curah. Dalam suatu desain, sebelum menentukan atau memprediksi penurunan tekanan aliran solid-gas di dalam pipa pada mesin pneumatic conveying, tahap pertama yang harus diketahui terlebih dahulu adalah pola aliran yang terjadi pada aliran tersebut. Hal ini disebabkan karena masing-masing pola aliran yang terbentuk mempunyai karakteristik lokal maupun karakteristik rata-rata penurunan tekanan yang berbeda pada aliran. Pada pola aliran tertentu menghasilkan efisiensi produksi yang lebih baik dibanding dengan pola aliran yang lain, begitu juga pada pola aliran tertentu dapat pula mempunyai tingkat bahaya yang lebih besar terhadap sistem dibanding pola aliran yang lain [2].

Hu dkk [3] menyatakan bahwa dalam pengukuran aliran dua fasa, identifikasi pola rezim aliran yang benar merupakan dasar untuk mempelajari parameter-parameter yang lain dalam aliran. Hal ini juga mempengaruhi secara langsung terhadap penurunan tekanan, stabilitas, dan keamanan sistem dua fase. Pola aliran dapat diidentifikasi dengan berbagai cara antara lain densitometer sinar gamma [4], metode impedansi listrik, fluktuasi beda tekanan $[5,6,7]$, metode visualisasi $[8,9,10]$, pengolahan citra $[11,12,13]$, dan metode ultrasound [14]. Namun demikian, metode identifikasi di atas merupakan identifikasi pola aliran dua fase gascair. Saat ini, identifikasi pola aliran solid-gas sedang menarik perhatian para peneliti, tetapi masih sedikit referensi dan pengalaman di bidang solid-gas yang tersedia. Kaman dan Lawat [15], mengajukan peta pola aliran solid-gas yang cukup lengkap, menggunakan bilangan Archimides sebagai sumbu x dan bilangan Reynold sebagai sumbu y. Namun demikian penggunaan Peta Karman dan Lawat [15] tidak cukup sederhana. Oleh karena itu pada artikel ini diusulkan peta pola aliran dua fasa solid-gas yang cukup sederhana dengan menggunakan kecepatan superfisial gas sebagai sumbu $\mathrm{x}$ dan laju aliran masa bahan curah sebagai sumbu y.

\section{METODOLOGI PENELITIAN}

Fasilitas peralatan yang digunakan dalam penelitian ini seperti yang terlihat pada Gambar 1, berada di Laboratorium Teknik Mesin, Fakultas Teknik Universitas Muria Kudus. Eksperimen telah dilakukan pada sistem pneumatics conveying, dimana udara disuplai dari sebuah kompresor dengan laju aliran maksimum $335 \mathrm{lpm}$, tekanan maksimum 10 bar. Kompresor dihubungkan ke pipa oleh a selang fleksibel dengan diameter dalam $8,5 \mathrm{~mm}$ dan panjang $1,5 \mathrm{~m}$. Sistem pneumatics conveying memiliki panjang pipa horizontal $2 \mathrm{~m}$ setelah feeding tee, panjang pipa miring $2 \mathrm{~m}$ dan panjang pipa horizontal sebelum separator $2 \mathrm{~m}$. Pipa memiliki diameter dalam 2,54 mm, terbuat dari akrilik transparan. Konfigurasi pneumatics conveying yang dipakai untuk mentranportasikan butiran jagung secara detail dapat dilihat pada Gambar 1.

Laju aliran masa butiran ditentukan oleh rasio massa yang dipindahkan oleh rotary valve untuk mengosongkan hopper pengumpan dalam waktu tertentu, dimana rotary valve memasukkan padatan ke sistem pengangkutan pneumatik. Butiran jagung yang keluar dari rotary valve dan udara yang berasal dari tabung kompresor mengalir melalui flow meter dan bercampur pada feeding tee. Kecepatan superfisial udara 
$\left(J_{G}\right)$ diatur dari kecepatan $2 \mathrm{~m} / \mathrm{s}$ sampai dengan $10 \mathrm{~m} / \mathrm{s}$. Sedangkan laju aliran massa solid $\left(\dot{\boldsymbol{m}}_{\mathrm{S}}\right)$ diatur dari $2,2 \mathrm{~kg} /$ menit sampai dengan $11 \mathrm{~kg} /$ menit. Pengamatan dilakukan pada jarak pipa $4750 \mathrm{~mm}$ sampai $5250 \mathrm{~mm}$ dari pengumpan. Pola aliran dua fase solid-gas secara visual diamati dengan menggunakan kamera FUJI XA5 dengan kecepatan perekaman 30 sampai 120 fps (frame per second). Fenomena aliran yang terjadi pada pipa ditangkap oleh kamera melalui bayangan cahaya yang terdapat di celah-celah partikel solid.

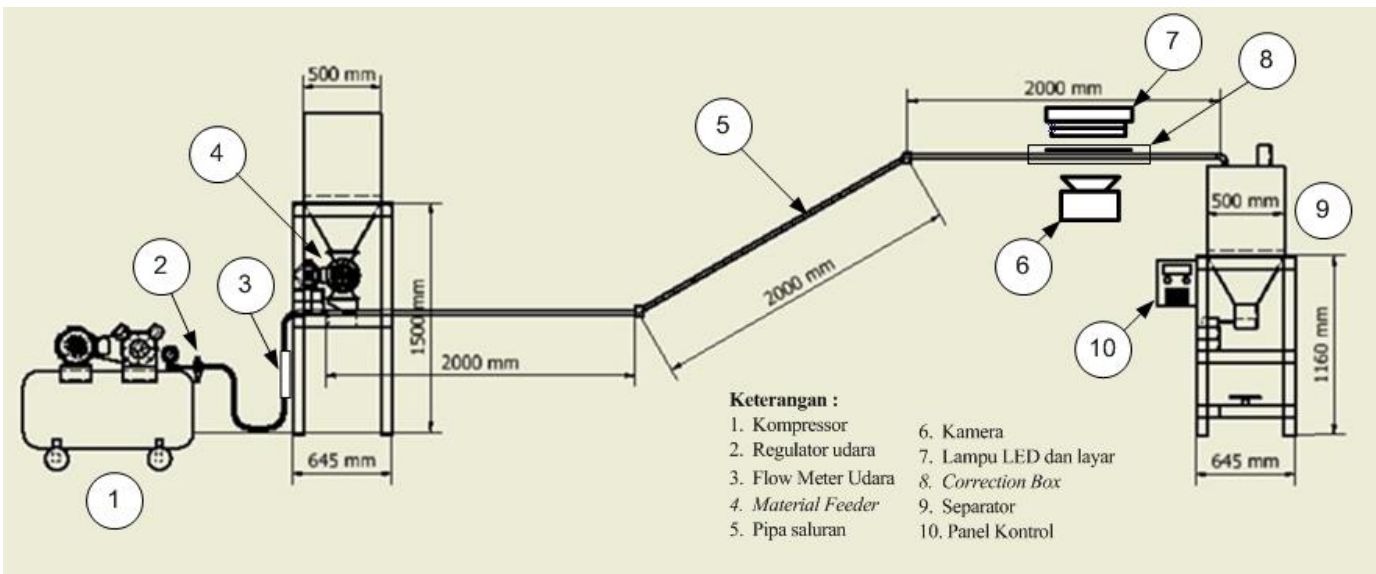

Gambar. 1 Skema alat penelitian

\section{HASIL DAN PEMBAHASAN}

\subsection{Identifikasi Pola Aliran}

Studi eksperimen mengenai pola aliran dua fasa solid-gas dilakukan melalui metode visualisasi, dilakukan pada daerah berkembang penuh (fully developed) terutama pada pipa 25,4 $\mathrm{mm}$. Data visual diambil dengan menggunakan kamera video kecepatan tinggi. Pola yang berhasil diidentifikasi meliputi pola aliran dune flow, non-uniform Suspended, slug flow dan packed bed. Hasil visualisasi pola-pola tersebut dapat dijabarkan sebagai berikut :

\section{a. Pola Aliran Dune Flow}

Pola aliran dune flow adalah pola aliran dimana partikel-partikel mengendap menyerupai bukit yang diam namun partikel-partikel pada pada bagian atas bukit disapu oleh aliran gas partikelpartikel tersebut berpindah dari satu bukit ke bukit lainnya. Pola aliran ini terjadi pada laju aliran massa solid rendah dan kecepatan gas rendah. Gambar 2 menunjukkan contoh visualisasi pola aliran dune flow yang terjadi pada laju aliran massa jagung $\left(\dot{m}_{\mathrm{S}}\right)=2,2 \mathrm{~kg} / \mathrm{menit}$ dan kecepatan superfisial gas antara $\mathbf{J}_{\mathrm{G}}=4 \mathrm{~m} / \mathrm{s}$.

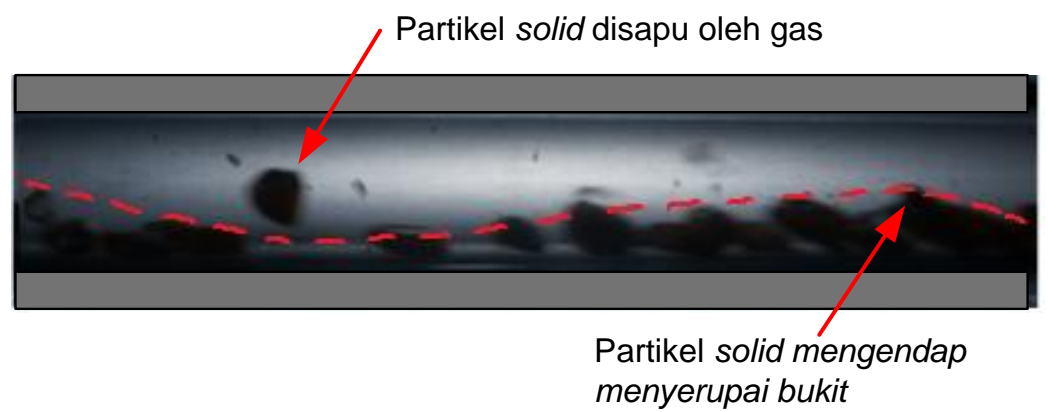

Gambar 2 Contoh Visualisasi Pola Dune Flow pada $\dot{m}_{\mathrm{S}}=2,2 \mathrm{~kg} /$ menit dan $\mathrm{J}_{\mathrm{G}}=4 \mathrm{~m} / \mathrm{s}$ 


\section{b. Pola Non-uniform Suspended Flow}

Pola aliran Non-uniform Suspended mempunyai karakteristik dimana partikel-partikel mengalir secara khusus di bagian bawah pipa. Pada eksperimen yang telah dilakukan, jenis pola dimana partikel-partikelnya terdistribusi secara merata pada arah melintang pipa di sepanjang pipa (homogenous flow) tidak ditemukan. Hal dikarena partikel jagung mempunyai diameter hidrolis yang cukup besar $(\varnothing= \pm 6 \mathrm{~mm}$ ). Pola aliran Non-uniform Suspended terjadi pada kecepatan superfisial gas tinggi dan laju aliran massa solid rendah. Gambar 3 menunjukkan contoh visualisasi pola aliran Non-uniform Suspended pada laju aliran massa jagung $\left(\dot{m}_{\mathrm{S}}\right)$ 2,2 kg/menit dan kecepatan superfisial udara $8 \mathrm{~m} / \mathrm{s}$.

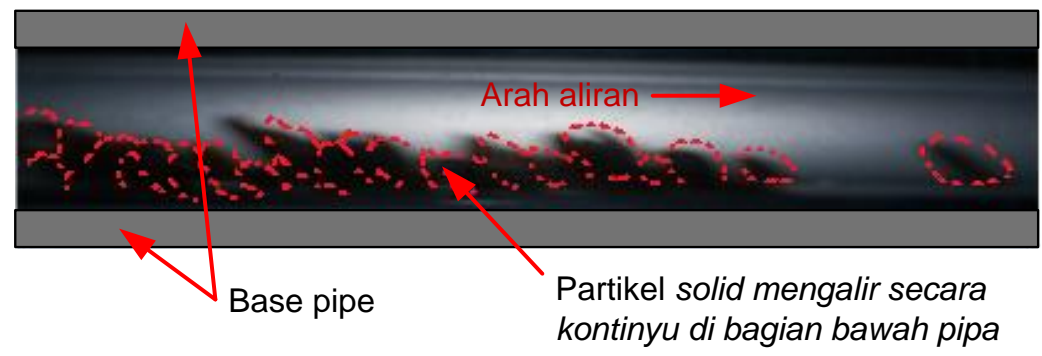

Gambar 3. Contoh Visualisasi Pola Non-uniform Suspended pada $\dot{m}_{\mathrm{S}}=2,2 \mathrm{~kg} /$ menit dan $\mathrm{J}_{\mathrm{G}}=4 \mathrm{~m} / \mathrm{s}$

\section{c. Pola Aliran Slug Flow}

Pada saat partikel memasuki pipa pengangkutan, partikel cenderung mengendap sebelum sepenuhnya dipercepat oleh aliran gas. Jika efek inersia lebih besar terhadap berat partikel maka bukit partikel yang terbentuk tersapu ke hilir menciptakan distribusi longitudinal partikel yang tidak merata disepanjang pipa. Pola aliran ini dikenal dengan pola slug flow. Gambar 4, menunjukkan contoh Visualisasi pola aliran slug flow pada laju aliran massa jagung $\left(\dot{m}_{\mathrm{S}}\right) 6,7 \mathrm{~kg} / \mathrm{menit}$ dan kecepatan superfisial udara $6 \mathrm{~m} / \mathrm{s}$.

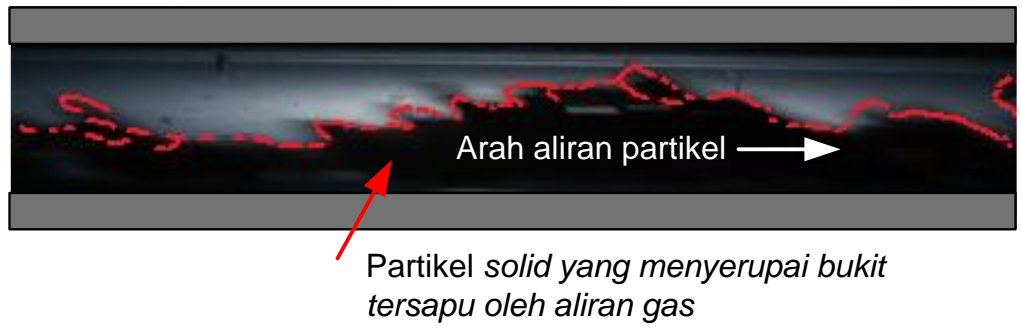

Gambar 4. Contoh Visualisasi Pola slug flow pada $\dot{m}_{\mathrm{S}}=2,2 \mathrm{~kg} / \mathrm{menit}$ dan $\mathrm{J}_{\mathrm{G}}=4 \mathrm{~m} / \mathrm{s}$

\section{d. Pola Aliran Packed Bed}

Pada saat kecepatan superfisial gas rendah dan seiring penambahan laju aliran massa partikel, maka akan terbentuk pola aliran packed bed. Pada pola ini partikel-partikel tampak akan mengisi keseluruhan pipa dan aliran gas mengalir melalui celah-celah partikel tersebut. Pada kondisi ini gerakan partikel akan sangat lambat mendekati kondisi stasioner. Gambar 5, menunjukkan contoh visualisasi pola aliran packed bed pada laju aliran massa jagung $\left(\dot{m}_{\mathrm{S}}\right)=8,9 \mathrm{~kg} / \mathrm{menit}$ dan kecepatan superfisial udara $4 \mathrm{~m} / \mathrm{s}$. 


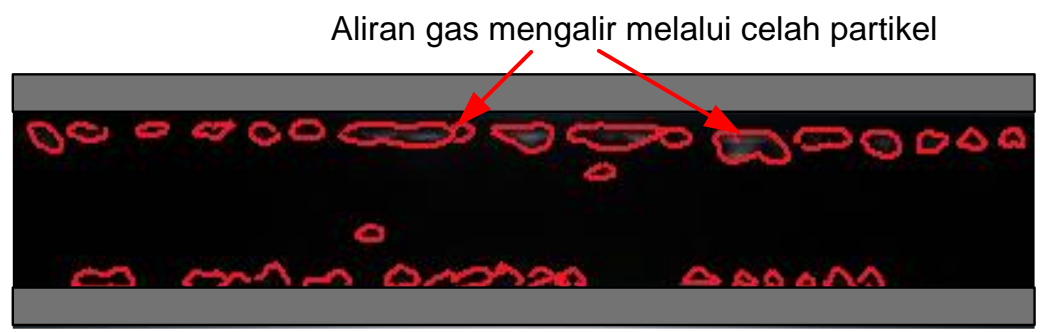

Gambar 5. Contoh Visualisasi Pola Packed Bed pada $\dot{m}_{\mathrm{S}}=8,9 \mathrm{~kg} / \mathrm{menit}$ dan $\mathrm{J}_{\mathrm{G}}=4 \mathrm{~m} / \mathrm{s}$

\subsection{Peta Pola Aliran}

Pola aliran yang terbentuk dipengaruhi oleh laju aliran massa solid $\left(\dot{m}_{\mathrm{S}}\right)$ dan kecepatan superfisial gas $\left(J_{G}\right)$ yang ditentukan. Berdasarkan pola-pola aliran yang berhasil diidentifikasi, selanjutnya disusun peta pola aliran seperti yang ditunjukkan pada Gambar 6. Pada Gambar 6 terlihat bahwa pada nilai $\dot{m}_{\mathrm{s}}$ kecil dan $J_{G}$ yang kecil, pola aliran yang terbentuk adalah dune flow. Seiring dengan peningkatan nilai $J_{G}$ maka penumpukan partikel di bawah pipa tersapu oleh aliran gas dan aliran akan bertransformasi menjadi non uniform suspended flow. Sedangkan pada nilai $J_{G}$ kecil dan nilai $\dot{m}_{\mathrm{S}}$ cukup besar maka akan terbentuk pola packed bed. Seiring dengan peningkatan nilai $J_{G}$ maka pola aliran akan bertransformasi menjadi slug flow. Pola aliran yang disarankan untuk proses operasi mesin pneumatic conveying adalah pola aliran non-uniform suspended flow dan slug flow

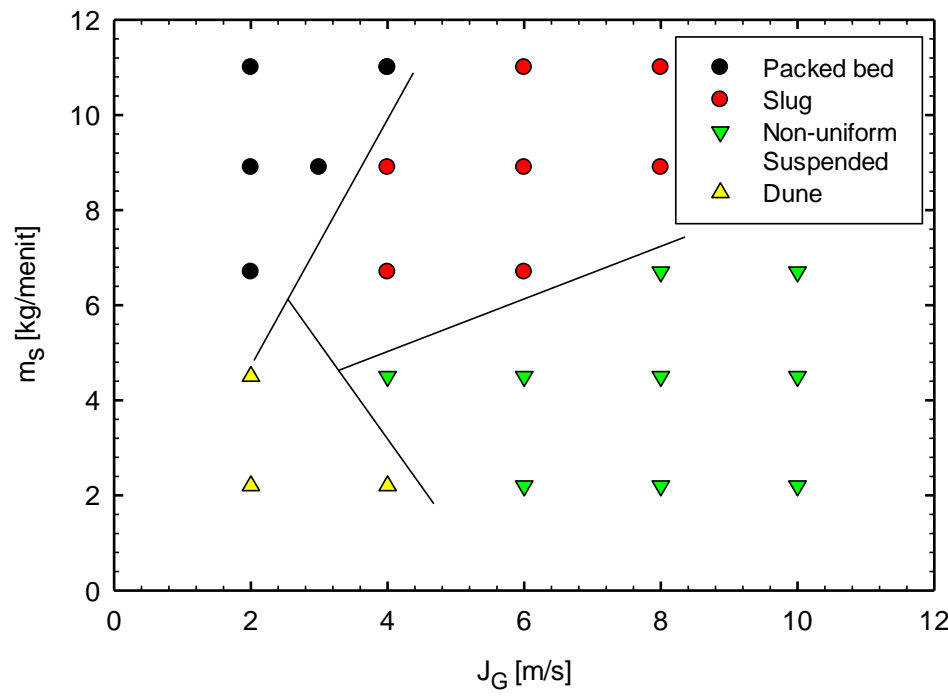

Gambar 6 Peta Pola Aliran Solid-Gas pada Pipa $\varnothing 24,5 \mathrm{~mm}$

\section{KESIMPULAN}

Setelah melakukan studi eksperimen mengenai pola aliran dua fasa solid-gas pada mesin pneumatic conveying dengan metode visualisasi, dapat disimpulkan sebagai berikut:

a. Pola yang berhasil diidentifikasi meliputi pola aliran dune flow, non-uniform Suspended, slug flow dan packed bed.

b. Pada kondisi nilai $\dot{m}_{\mathrm{S}}$ kecil dan $J_{G}$ yang kecil, pola aliran yang terbentuk adalah dune flow. Seiring dengan peningkatan nilai $J_{G}$ maka penumpukan partikel di bawah pipa tersapu oleh aliran gas dan aliran akan bertransformasi menjadi non uniform suspended flow. 
c. Pada kondisi nilai $J_{G}$ kecil dan nilai $\dot{m}_{\mathrm{S}}$ cukup besar maka akan terbentuk pola packed bed. Seiring dengan peningkatan nilai $J_{G}$ maka pola aliran akan bertransformasi menjadi slug flow.

d. Pola aliran yang disarankan untuk proses operasi mesin pneumatic conveying adalah pola aliran non-uniform suspended flow dan slug flow

\section{DAFTAR PUSTAKA}

[1] Bhatia, A., 2019. Pneumatic Conveying Systems. Chemical Engineering (New York). Continuing Education and Development, Inc, pp.1-57..

[2] Santoso, B., Indarto, I., Deendarlianto, D. and Thomas, S.W., 2012. Fluktuasi beda tekanan dari pola aliran slug air-udara pada aliran dua fase searah pipa horizontal. ROTASI, 14(2), pp.1-6..

[3] Hu, H.L., Zhang, J., Dong, J., Luo, Z.Y. and Xu, T.M., 2011. Identification of gas-solid twophase flow regimes using Hilbert-Huang transform and neural-network techniques. Instrumentation Science and Technology, 39(2), pp.198-210.

[4] Fischer, F. and Hampel, U., 2010. Ultra fast electron beam X-ray computed tomography for two-phase flow measurement. Nuclear Engineering and Design, 240(9), pp.2254-2259..

[5] Matsui, G., 1986. Automatic identification of flow regimes in vertical two-phase flow using differential pressure fluctuations. Nuclear Engineering and Design, 95, pp.221-231..

[6] Wibowo, R., Hudaya, A.Z. and Kabib, M., 2015. Studi Eksperimen Mengenai Sub-sub Pola Aliran Stratified Pada Aliran Dua Fasa Searah Berdasar Fluktuasi Beda Tekanan Pada Pipa Horisontal. Simetris: Jurnal Teknik Mesin, Elektro dan Ilmu Komputer, 6(2), pp.385-390.

[7] Alqoshmal, Y.M., Hudaya, A.Z., Dinaryanto, O., Widyatama, A., Deendarlianto and Indarto, 2018, August. The characteristics of the pressure gradient air-water stratified two-phase flow in horizontal pipes. In AIP Conference Proceedings (Vol. 2001, No. 1, p. 030004). AIP Publishing LLC.

[8] Dinaryanto, O., Hudaya, A.Z., Deendarlianto, D. and Indarto, I., 2018, November. The Visualization Study on the Slug Flow Mechanisms of the Air-Water Two-Phase in a $50 \mathrm{~mm}$ Horizontal Pipe. In Conference SENATIK STT Adisutjipto Yogyakarta (Vol. 4, pp. 87-93).

[9] Rahmandhika, A., Dinaryanto, O., Widyatama, A., Hudaya, A.Z., Indarto and Deendarlianto, 2018, August. Visualization study in the transition flow pattern of stratified to slug flow of airwater two phase flow in a horizontal pipe. In AIP Conference Proceedings (Vol. 2001, No. 1, p. 030003). AIP Publishing LLC.

[10] Hudaya, A.Z., Kuntoro, H.Y., Dinaryanto, O., Deendarlianto and Indarto, 2016, June. Experimental investigation on the interfacial characteristics of stratified air-water two-phase flow in a horizontal pipe. In AIP Conference Proceedings (Vol. 1737, No. 1, p. 040012). AIP Publishing LLC.

[11] Widyatama, A. and Dinaryanto, O., 2018. The development of image processing technique to study the interfacial behavior of air-water slug two-phase flow in horizontal pipes. Flow Measurement and Instrumentation, 59, pp.168-180.

[12] Hudaya, A.Z., Widyatama, A., Dinaryanto, O. and Juwana, W.E., 2019. The liquid wave characteristics during the transportation of air-water stratified co-current two-phase flow in a horizontal pipe. Experimental Thermal and Fluid Science, 103, pp.304-317.

[13] Kuntoro, H.Y., Hudaya, A.Z., Dinaryanto, O., Majid, A.I. and Deendarlianto, 2016, June. An improved algorithm of image processing technique for film thickness measurement in a horizontal stratified gas-liquid two-phase flow. In AIP Conference Proceedings (Vol. 1737, No. 1, p. 040010). AIP Publishing LLC.

[14] Rahiman, M.H.F., Rahim, R.A., Rahiman, M.H.F. and Tajjudin, M., 2006. Ultrasonic transmission-mode tomography imaging for liquid/gas two-phase flow. IEEE Sensors Journal, 6(6), pp.1706-1715.

[15] Kalman, H. and Rawat, A., 2020. Flow regime chart for pneumatic conveying. Chemical Engineering Science, 211, p.115256. 